\title{
Editorial
}

\section{The global financial crisis, health and health care}

\author{
JOHN APPLEBY* \\ The King's Fund, London, UK \\ JAN-KEES HELDERMAN \\ Institute for Management Research, Nijmegen School of Management, Radboud University Nijmegen, the Netherlands \\ SARAH GREGORY \\ The King's Fund, London, UK
}

From the early outward signs of a collapse in the US sub-prime mortgage market in the spring of 2007, the global banking crisis unfolded. Financial institutions thought too big to fail, failed. In the summer of 2007 the French bank BNP Paribas ceased activity in three hedge funds that specialized in US mortgage debt. Meanwhile, in Britain, on 14th September investors in the bank, Northern Rock, withdrew over $£ 1$ billion in the biggest run on a bank in the United Kingdom for more than a century. The bank was nationalized in February of 2008 after two private bids to take it over failed. In the autumn of 2007 more and more banks started to announce losses. Across the Atlantic, in the spring of 2008 the US investment bank Bear Sterns was merged with JP Morgan Chase as part of the Federal Reserve Bank's rescue package. By the autumn of 2008 the seizure in bank lending and the scale of the financial problem started to accelerate with the decision of the US government not to support Lehman Brothers investment bank. On 15th September, Lehman's filed for bankruptcy.

At the April meeting of the G20 group of countries in 2009 a commitment was made to co-ordinate further financial support for the banking industry globally as well as fiscal stimulus through quantitative easing and other measures to try and dampen recessions in many countries. By 2009, the cost of the financial support to banks and the world economy in general reached a total of around $£ 7.1$ trillion, a fifth of the total annual global economy (Daily Telegraph, 2009). In the United Kingdom, the cost of support by the government was estimated at around $£ 1.23$ trillion - over $80 \%$ of the country's annual gross domestic product (GDP). Interest rates were cut severely - UK central bank interest rates hit their lowest level since 1694 at just 0.5\% (Bank of England, 2009).

"Correspondence to: John Appleby, Chief Economist, The King's Fund, 11-13 Cavendish Square, London W1G 0AN, UK. Email: j.appleby@kingsfund.org.uk 


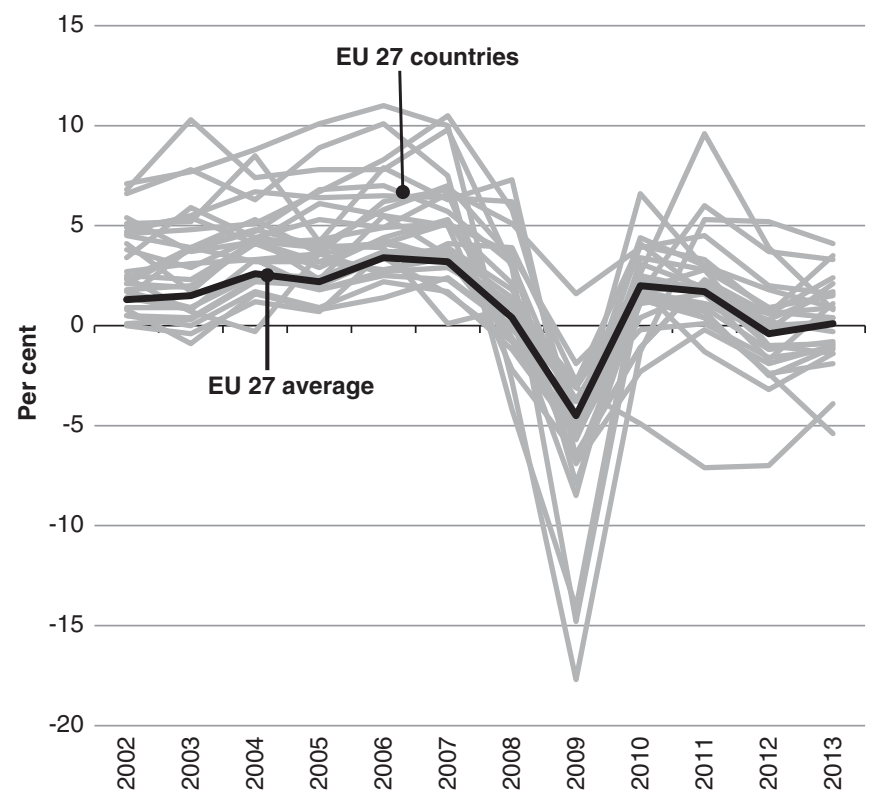

Figure 1. Real GDP, EU 27 countries: annual real changes: 2002-2013

Source: Eurostat http://epp.eurostat.ec.europa.eu/tgm/table.do?tab=table\&plugin=1\& language $=$ en $\&$ pcode $=$ tec 00115

The impact of the recession on economies was ubiquitous; in 2009 real GDP fell across the EU 27 countries by nearly 5\%. All EU 27 countries (apart from Poland) saw GDP fall in real terms (see Figure 1). While by 2013 all EU 27 countries' economies had improved, the difference between the previous peak growth and 2013 was 1.4 percentage points lower across the EU 27 on average, with real GDP per capita still 2.8 percentage points lower than the previous peak.

The huge cost of the banking sector rescue packages coupled with the costs of the ensuing recession (lower tax revenues, higher non-discretionary welfare spending) left governments with large budget deficits. Across the European Union, in 2009 , the average deficit was $6.9 \%$ - equivalent to $€ 808$ billion. Every one of the EU 27 countries' governments ran a deficit (see Figure 2).

Given the huge financial scale of the banking crisis and great recession what have been the consequences for public policy and public spending and in particular for health care? In this special issue of Health Economics Policy and Law we draw together selected papers previously presented at two meetings of the European Health Policy Group in Copenhagen and in London in 2012, together with a number of invited contributions including three overview papers from different perspectives and two forward looking essays.

Let us start with the figures. One almost immediate effect of the macroeconomic crisis seems to be that European countries succeeded in slowing down (public) 


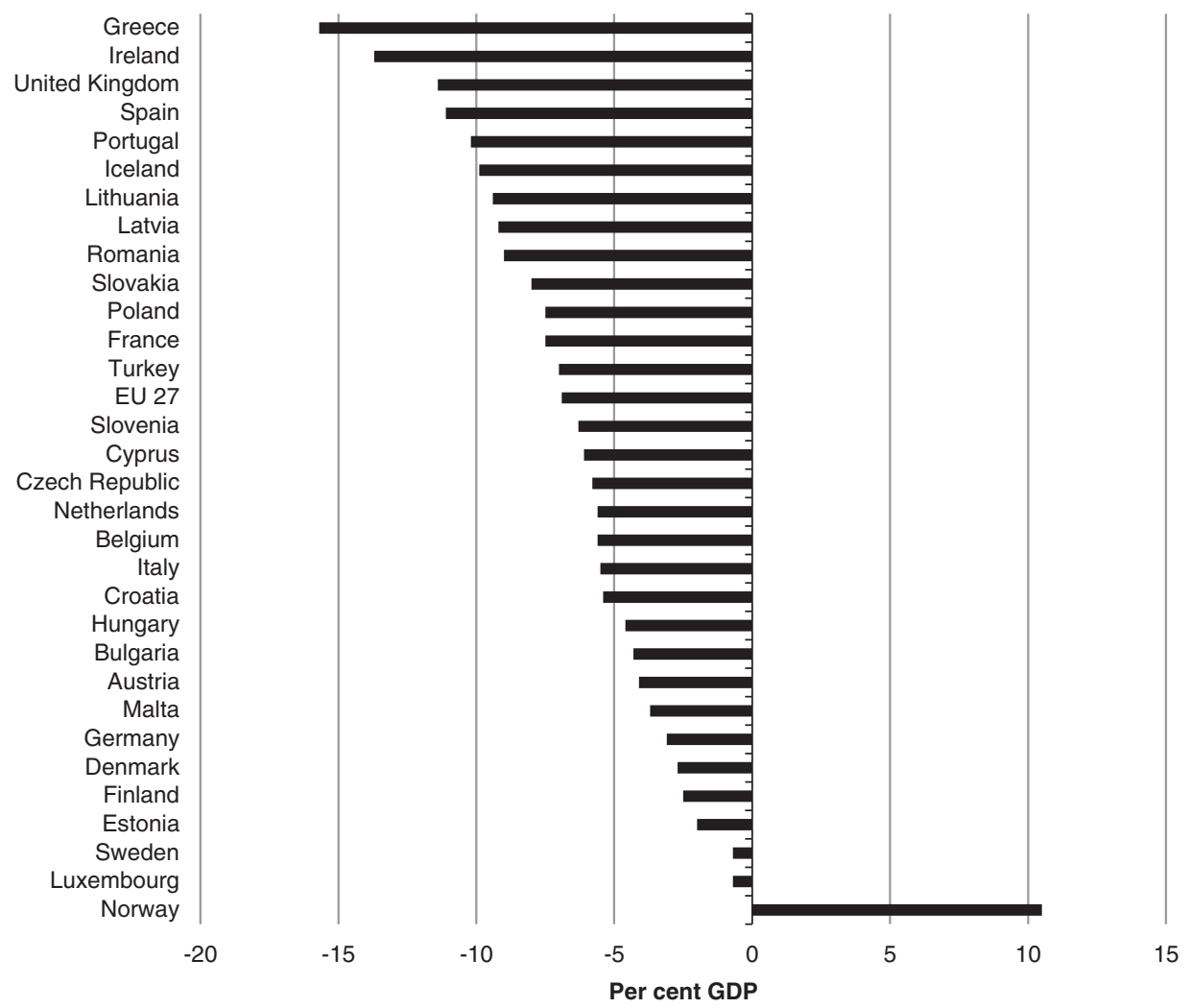

Figure 2. Government deficits, 2009 (per cent GDP)

Source: Eurostat http://appsso.eurostat.ec.europa.eu/nui/submitViewTableAction.do?dvsc=5

health expenditures for the first time since the 1960s. In their overview article, David Morgan and Roberto Astolf, both working for the OECD Health Division, examine in detail the observed downturn in health expenditure growth, analysing which countries and which sectors of health spending were most affected. They show that there is wide variation across European countries as to the extent of the slowdown of expenditures, while some countries outside of Europe continuing to see significant growth in health spending. Most of the slowdown has been achieved in pharmaceutical spending and in areas of public health and prevention. Another conclusion that deserves attention is that the decrease in health spending growth has to a large extent been driven by reductions in public spending through the introduction of various measures or acceleration of reforms. Morgan and Astolf found some evidence of a shift to private financing of health care through cost-sharing measures although private spending has also seen slower growth since 2009. Two tentative conclusions can be derived from their paper, first, the Global Financial Crisis (GFC) has a special European dimension which of course can be related to the European Monetary Union and the Euro-crises that came 
along with the GFC. Second, there appears to be a relation between ongoing reform efforts in various countries and the sudden outbreak of the GFC in 2008.

Writing from a political science perspective Helderman argues that the macroeconomic crisis might be conceived of as an exogenous shock factor that not only undermines the fiscal sustainability of European welfare states and their health care systems, but also urges governments and other stakeholders to fundamentally rethink and reform their health care systems. Health has been prominent on the European agenda since the Lisbon Summit of 2000, with the EU especially worried about unsustainable health care expenditure. But since the outbreak of the GFC, the EU has claimed authority over health system reforms alongside the responsibilities of its Member States in an increasingly coercive and persuasive way. So another effect of the GFC might be that the EU has moved from being an exogenous actor in policy making to become an enduring stakeholder in European health care policies. This is most clear in the exceptional circumstances of the bail out programmes for Ireland, Portugal and Greece. The creation of the Economic Semester may further institutionalize the European influence on the health systems of the Member States and may create new venues for the EU to interfere in domestic health system reforms.

The GFC has certainly intensified the imperative for improved efficiency in health care systems across Europe. Changes in demography and expensive advances in medical technology had already prompted governments to think about how to treat more patients with less money. The GFC intensified this trendefficiency enhancing reforms are the last resort for governments who wish to avoid painful choices in their health care systems. Benedict Rumbold and colleagues present a literature review of the international evidence on how to improve productive efficiency in secondary care settings. More specifically, they found five areas for reformist action aimed at improving efficiency including: tackling variation; thoughtful use of incentives by both national planning bodies and payer organizations; focusing on efficiency across all hospitals; measuring the right metrics, and using international comparisons.

Rumbold and colleagues also conclude that institutional conditions matter and these conditions differ across countries. There is one group of countries in Europe that seem to have been hit less severely by the GFC and better prepared. These countries, Finland, Sweden and Denmark, are the subject of the paper by Juhani Lehto, Karsten Vrangbæk and Ulrika Winblad. They show how the policies used in these countries to recover from earlier financial crises have impacted upon the policy reactions to the GFC. More specifically, they show how the crises in the 1980s (Denmark) and early 1990s (Finland and Sweden) served as focusing events and became reference points for policy adjustments aimed to facilitate stronger control of health expenditures. This had led to the institutionalization of stronger budget controls as well as a general emphasis on productivity increases in these three health care systems. Reactions to deep recessions have been mainly temporary adjustments and acceleration of changes already prepared before economic crisis. 
Somewhat provocatively, the authors argue that the current economic crisis in the three countries has not been 'good enough' to enable significant changes in the Nordic public, decentralized and equity oriented health systems. At the same time, however, changes such as the slow privatization in care funding and production and the adoption of new management practices indicate an ongoing paradigmatic change related to longer term societal, ideological and political developments rather than directly to economic crises or growth.

David Stuckler, Aaron Reeves, Marina Karanikolos and Martin McKee ask why researchers studying the health effects of economic crises have reached so many differing conclusions. More specifically, they discuss contemporary controversy in the social science and public health research in so far as it concerns our understanding the effects of the 'Great Recession' on people's health and well-being. Simply put, there is clear recognition that economic downturns significantly affect health, but views differ as to how. As with earlier crises, starting with the Great Recession of the 1920s, the current crisis has led to a rapid increase in research, especially from a public health perspective, but different philosophical approaches see different causalities and have led to differing interpretations. The authors conclude by calling for more interdisciplinary research that combines empirical findings with a search for plausible mechanisms and which looks not only at the effects of economic shocks but also at the mechanisms that offer protection against them.

Given all the uncertainties associated with the current crisis, how can we speculate about the future? We asked Nick Timmins and Rudolf Klein to make a start with this. Both authors are known for their profound historical knowledge and they write about what they think the responses to the GFC might mean for health in the future. Nick Timmins warns us that there are no data about the future and so his piece is based on assumption, presumption, trend analysis and speculation. Nevertheless, Timmins bases his optimism on previous predictions of doom that that did not come to pass because of unforeseen innovations and economic growth. Projections in the early 1970s suggested that by 2010, health spending in countries such as the original EU 6 would have doubled to $10 \%$ of GDP which was then seen as an unsustainable rate of growth. But it is precisely what happened and it turned out to be sustainable because the economy was roughly 2.5 times larger in real terms, so while health was taking a larger slice of total income, it was a larger slice of a very much larger cake - rising health expenditures proved to be affordable. On that basis if innovation continues and societies continue to adapt, and economies return to growth again, then there is no need for pessimism.

A similar argument is made by Rudolf Klein. He argues that over the past few decades discourse about health policy has changed very little, so there is good reason to be cautious about seeing the GFC as a watershed in the evolution of health care systems. Health systems in wealthy countries have been proved to be extremely resilient, so the GFC will be a turning point only if it marks the end of an era of economic optimism. 
The pessimistic view might be then that the future will be unlike the past - that governments might not follow the pattern of reverting to increased levels of health expenditure once an economic crisis has passed. Klein discusses three uncertain variables that are important when thinking about this future. One is uncertainty about future economic performance. Another is uncertainty about the future dynamics of health care. The third variable that Klein identifies may however be the most important one, that is, what will be the dominant paradigm of economic management and how will future Governments think about economic performance in the light of that paradigm. It is possible that Governments will commit to an economic model that emphasises keeping taxes low and national debt to a minimum.

It is probably too early to come to firm conclusions about the impact of the GFC on health care and public health and well-being. The papers in this special issue serve more as a research agenda than as evidence-based crisis studies. Stuckler et al. call for more interdisciplinary research, Helderman calls for political and policy analyses that go beyond the level of the nation state, especially now that the EU has become a stakeholder of its own (which may force governments to keep national debt and taxation low). Yet, apart from the bail out programmes, we try as long as possible to avoid painful choices by putting all our hopes on efficiency. Rumbold and colleagues call for empirical studies that test the prospects of these efficiency enhancing reforms in health care. The proof of the pudding is in the eating, but we have only had the starter yet and for the rest of the menu, we have chosen the courses that we know best.

\section{References}

Bank of England (2009), http://www.bankofengland.co.uk/statistics/Documents/rates/baserate. pdf [17 July 2014].

Daily Telegraph (2009), http://www.telegraph.co.uk/finance/newsbysector/banksandfinance/ 5995810/IMF-puts-total-cost-of-crisis-at-7.1-trillion.html [17 July 2014]. 